\title{
El hipérico fue similar a la imipramina para el tratamiento de la depresión leve a moderada
}

Comparison of St John's wort and imipramine for treating depression: randomised controlled trial. Helmut Woelk for the Remotiv/Imipramine Study Group BMJ 2000;321:536-9

\section{Objetivo}

Comparar la eficacia y tolerancia de Hypericum perforatum (Extracto de St John's o hipérico) versus imipramina en pacientes con depresión leve a moderada.

\section{Diseño}

Ensayo clínico aleatorizado, doble ciego, multicéntrico.

\section{Lugar}

Realizado en 40 clínicas de Psiquiatría, Medicina Interna y Medicina General. Alemania.

\section{Pacientes}

Se incluyeron 324 adultos ambulatorios con depresión: 157 fueron asignados a hipérico y 167 a imipramina. El $71 \%$ fueron mujeres; la mayoría entre 30 y 60 años. Del total 189 tenían depresión leve y 135 moderada. Los pacientes cumplían criterios diagnósticos de depresión según el CIE-10. Se excluyeron mujeres embarazadas o que estuvieran amamantando, aquellos que tuvieran antecedentes de alergia a algunas de las drogas usadas, que tuvieran otra enfermedad seria a juicio de los investigadores o enfermedad seria psiquiátrica, trastorno bipolar o consumo excesivo de alcohol o drogas. También se excluyeron participantes que hubieran recibido drogas psiquiátricas o que interactúen con las del estudio, dentro de los 14 días anteriores al reclutamiento (excepto benzodiacepinas en forma intermitente).

\section{Intervención}

$75 \mathrm{mg}$ de imipramina dos veces al día o $250 \mathrm{mg}$ de hipérico dos veces al día durante seis semanas.

\section{Medición de resultados principales}

Los resultados principales se midieron por la evolución de la depresión, con la escala de depresión de Hamilton, la escala de impresión clínica global y la escala de impresión global del paciente. El análisis se realizó por intención de tratar.

\section{Resultados}

La mejoría de la depresión fue similar y significativa en ambos grupos. Grupo hipérico: reducción de escala de Hamilton desde de 22,4 a 12,00 a las 6 semanas de tratamiento. Grupo imipramina: de un basal de 22,1 a 12,75. Los resultados fueron similares al usar las escalas de impresión global clínica del medico o la asignada por el paciente. En la subescala de ansiedad-somatizacion del test de Hamilton se observó una pequeña ventaja a favor del hipérico. Los eventos adversos para el hipérico fueron 39\% vs $63 \%$ de la imipramina $(p<0.01)$.

Tabla 1. Efectos del tratamiento a las seis semanas.

\begin{tabular}{|c|c|c|c|c|}
\hline & $\begin{array}{c}\text { Hipérieo } \\
n=157\end{array}$ & $\begin{array}{c}\text { Imipramina } \\
n=167\end{array}$ & $\begin{array}{l}\text { Diferencia en el valor } \\
\text { de reduceión (IC 95\%) }\end{array}$ & Valor de P \\
\hline $\begin{array}{l}\text { Variable primaria } \\
\text { Escala de Hamilton } \\
\text { Promedio de valores } \\
\text { finales alcanzados }\end{array}$ & 12.00 & 12,75 & $\begin{array}{c}-0,75 \\
(-1,90 \mathrm{a} 0,40)\end{array}$ & 0,20 \\
\hline $\begin{array}{l}\text { Variables secundarias } \\
\text { Promedio en la sub-escala } \\
\text { de Hamilton de ansiedad } \\
\text { y somatización }\end{array}$ & 3,79 & 4,26 & $\begin{array}{c}-0,48 \\
(-0,91 \mathrm{a}-0,04)\end{array}$ & 0,03 \\
\hline $\begin{array}{l}\text { Promedio en la escala de } \\
\text { impresión clínica global }\end{array}$ & 2,22 & 2,42 & $\begin{array}{c}-0,20 \\
(-0,42 a 0,02)\end{array}$ & 0,08 \\
\hline $\begin{array}{l}\text { Promedio en la escala de } \\
\text { impresión del paciente }\end{array}$ & 2,44 & 2,60 & $\begin{array}{c}-0,16 \\
(-0,40 \text { a } 0,09)\end{array}$ & 0,20 \\
\hline
\end{tabular}

Tabla 2. Porcentaje de cambio en la Escala de Hamilton

\begin{tabular}{l|c|c|c}
\hline $\begin{array}{l}\text { Cambio en el valor } \\
\text { de la escala de Hamilton }\end{array}$ & $\begin{array}{c}\text { Hipéricum } \\
\mathbf{n = 1 5 7}\end{array}$ & $\begin{array}{c}\text { Imipramina } \\
\mathbf{n = 1 6 7}\end{array}$ & RR (IC 95\% ) \\
\hline$\geq 50 \%$ de reducción & $68(43 \%)$ & $\begin{array}{c}67(40 \%) \\
(0,83 \text { a } 1,40)\end{array}$ & 1.08 \\
\hline$\geq 20 \%$ de reducción & $115(73 \%)$ & $\begin{array}{c}109(65 \%) \\
(0,97 \text { a } 1,30)\end{array}$ & 1,12 \\
\hline$\geq 10$ puntos de reducción & $77(49 \%)$ & $\begin{array}{c}75(45 \%) \\
(0,87 \text { a } 1,38)\end{array}$ & 1,09 \\
\hline
\end{tabular}

\section{Conclusiones}

El extracto de la planta Hypericum Perforatum es terapéuticamente equivalente a la imipramina en el tratamiento de la depresión leve a moderada y es una terapéutica mejor tolerada por los pacientes.

Fuente de financiamiento: Bayer AG

\section{Comentario}

El Hypericum Perforatum o Hierba de San Juan es originaria de Europa y Asia, y desde la antigüedad se usaba contra las posesiones demoníacas. En 1525, Paracelso elogió sus poderes contra "Ios fantasmas" y "las fantasías". El lenguaje popular la denomina "La sangre de los dioses". ${ }^{1}$ En Argentina crece en las regiones de Córdoba, Catamarca, La Rioja, San Juan y San Luis.? Si bien su uso en medicinas alternativas data de largo tiempo, su incorporación a la industria farmacéutica comienza a fines de la década del 80' en Europa posiblemente influenciada por la presión del mercado consumidor que comienza a utilizar formas más naturales y menos nocivas de tratar los viejos problemas. Desde entonces, su popularidad ha ido creciendo a ritmos insospechados: en Alemania, desde que se lanzó al mercado, en 1990, se vende 4 veces más que la fluoxetina, la droga líder de la última generación de antidepresivos.

Hace varias décadas se viene evaluando el efecto del extracto de Hypericum Perforatum sobre la depresión. Se han identificado unos 23 ensayos publicados de diferente rigor metodológico, en- tre ellos 6 más recientes comparan la eficacia de psicofármacos de uso corriente como la amitriptilina, imipramina ${ }^{3}$ y maprotilina en depresión, aún en casos de depresión severa. Si bien la eficacia del extracto de Hypericum quedó demostrada en estos estudios, siempre existieron críticas metodológicas de los mismos.

Este trabajo intenta una vez más comparar la eficacia del extracto de Hypericum frente a la imipramina utilizando escalas de depresión ${ }^{4}$ de uso habitual por el médico de atención primaria, y prestando particular atención metodológica, sin demostrar diferencias en la eficacia frente a un tratamiento "clásico".

Finalmente quiero recordar que la medicina aborigen de nuestro gran continente americano, supo acuñar y conocer un gran herbolario de uso medicinal, entre los que cabe destacar la digital, la efedra, la malva y el hipérico. Los usos descriptos fueron muy parecidos a los que nosotros aplicamos tras su industrialización. Si nosotros hubiéramos prestado más atención a estas descripciones (como en definitiva la prestaron las empresas farmacéuticas del viejo mundo), otra quizás hubiera sido la historia.

\section{Dr. Marcelo Angel Ikonikoff [ Unidad de Medicina Familiar y Preventiva. Hospital Italiano de Buenos Aires ]}

Referencias

1. Revista Que Pasa 1436. 19 al 26 de Octubre de 1998.Monica Infante Chile

2 La vuelta a los vegetales. Carlos Hugo Burgstaller Chiriani. Ed. Edicial mayo 1994

3. Philipp M, Kohnen R, Hiller KO. Hypericum extract versus imipramine or placebo in patients with moderate depression: randomised multicentre study of treatment for eight weeks. BM. 1999: 319: 1534-1538

4. Hamilton M. Development of a rating scale for primary depressive illness. Br J Soc Clin Psychol 1967; 6: 278-296. 